\title{
CONFERENCE WORKFLOW AS LONG-TERM ACTIVITY WITHIN ENGLISH FOR SPECIAL PURPOSES (ESP) COURSE
}

\author{
Natalia Bogach, Elena Boitsova, Yurij Lezhenin, Artyom Zhuikov \\ Peter the Great Saint-Petersburg Polytechnic University, Russia \\ bogach@kspt.icc.spbstu.ru, el-boitsova@yandex.ru, lezhenin@kspt.icc.spbstu.ru, \\ zhuikov@kspt.icc.spbstu.ru
}

\begin{abstract}
Publication record is one of the key indicators of scientific research performance, which affects individual career perspectives. Experience in academic writing gives the authors a great advantage, as it promotes their personal growth through communication in modern scientific community. Research output presentation in accordance with academic writing standards is a specific skill that needs to be nurtured by a narrow focused education. The best age for academic writing training is studentship. An early introduction to academic writing does a benefit for future scientists and specialists, as it alleviates their insertion in scientific world. Although, a great attention is now being paid to academic English skills development, it seems to be useful to put into practice some active forms of learning to stimulate and encourage students in using English for their academic work. This paper presents the experience of conference workflow format applied for English for Special Purposes (ESP) course classes. 50 master students were involved. During a semester students were preparing an article based on their bachelor thesis. By the end of the semester these articles were peer-reviewed by student program committee and by the supervisor. Except a minor part of rejected articles (near $15 \%$ ), all the others were presented by students in a conference 5-7 minute speech, followed by a short discussion. Conference workflow was thus simulated. Conference workflow assumes mastering all the language competencies, namely, reading, writing, listening and speaking. Preparing to the conference implies students' break out of their comfort zone allowing at the same time to get in on a friendly learning environment, which brings up collaboration, invokes knowledge transfer, and increases the engagement and motivation.
\end{abstract}

Keywords: academic writing, written expression, presentation skills, conference workflow.

\section{Introduction}

Publishing is a very important component for any researcher. It has numerous benefits. Putting ideas together in a well-structured clear manner allows to share the results with other researchers. Scholar output serves for progress through professional community interaction. Moreover, making an article and getting important criticism from reviewers are the means of self-study and professional growth, when an author gets familiar with the main conferences and journals in herl/his field of knowledge. Thus, the written expression ability affects academic career greatly, and is to be developed by special training. Research result presentation in accordance with the academic writing standards is a specific skill that needs to be nurtured by a narrow focused education.

The best age for academic writing training is studentship. An early introduction to academic writing does a benefit for future scientists and specialists, as it alleviates their insertion in scientific world. Although, a great attention is now being paid to academic English skills development $[1 ; 2]$, it seems to be useful to put into practice some active forms of learning to stimulate and encourage students in using English for their academic work. A great benefit that can be produced from applying conference format as a learning methodology has been repeatedly reported in recent years [3; 4].

During the semester students were preparing an article based on their bachelor thesis. Near 50 students of master degree program enrolled to the English for specific purposes course were involved. This group of students was highly diverse both in the level of English (from the low- to the upperintermediate) and in their L1 language (mother tongue). Except Russian students, there was a share of students, whose L1 was Chinese or Arabic. Under these conditions, the authors searched for a methodology for active learning that boosts self-study being at the same time exciting and encouraging. Preparing to the conference implies certainly a break out of a comfort zone, but it allows to bring up student collaboration, invokes knowledge transfer, and increases the engagement and motivation.

\section{Materials and methods}

Conference workflow offers a universal instrument to master the core language competencies such as reading, writing, listening and speaking: 
- academic reading including scanning and skimming;

- written expression in academic style;

- socializing and communication when presenting papers and in the course of conference discussions.

Preparing a paper implied the following techniques and skills:

- LaTeX program to manage templates, text, graphics, formulae, reference list, etc.;

- bibliographical managers and tools (BibTeX, Mendeley, Zotero, etc.);

- conference management system (EasyChair).

Ten steps leading students to accomplish an academic paper prototype can be organized as 10 activities, offered to the students during the semester.

1. "Know your community".

The starting point for the beginners is to get to know their specific scientific community. Students are encouraged to define the focus of their academic context. One needs to find out, what conferences and journals are important in this specific field. Identifying academic conferences and journals defines the ecosystem of the community.

Alongside, one needs to figure out, what theories and concepts constitute the state-of-the-art in this very field and get know the influential researchers in this community. Students have to realize that getting familiar to the community is not a one-time event, but an iterative and continuous process that gives two major outcomes: first, it helps making a research, well-focused and accurate both in ideas to develop and terms to use; second, discovers names and ideas of people working on your topic.

An amount of reading while doing this activity can be very large, but students have to know that they are not obliged to read all the papers. They are recommended to make a recent ten years' bibliography of specific topics. At this point, they face the problem, how to sort papers in order to read the most relevant of them. This work can be done by classification of papers into essential papers and related papers. Thus, by reading articles students are asked to find few domains essential to their research focus as well as several domains that relate to their research. The difference between essential and related helps students position their future paper under the scientific context. Knowing the academic context of the research helps estimate the importance and relevance of their future work.

\section{1-1.5 weeks is a typical duration of this stage.}

2. Research design.

The goals of this activity are: to delimit the paper scope, pose the research questions; identify the research gap, and, thus, motivate and prove the originality of a scientific paper. This activity encompasses understanding of what had already been done in the field and where the border is that delimits what is already known from what was not investigated so far. This border is permanently moving while new theories, ideas and methods get proven as others get rejected or modified. Establishing a literature review is a way to specify the originality of a paper. Students realize that originality may cover several aspects including new empirical work, interpreting known ideas in a new way, giving new data to old problems, translating results from one technique to another.

Research design duration is $1-2$ weeks.

3. Literature review. Tools.

The objectives of a literature review are to identify the knowledge frontier and context of research questions. Students prepare keywords, various links to a research question, undertake search in databases like Google Scholar and others. They get acquainted with different types of citations and learn how to make a bibliography using BibTeX. Once they bring together their references, they need a tool to conduct them. Different types of bibliography managers can be very helpful for this purpose.

Activities 2 and 3 can be fulfilled in parallel and their total duration is up to 3 weeks.

This way after a month the students are ready to start writing.

4. IMRAD model and MRCI framework.

Two important abbreviations are discussed in this activity. The structure of an academic paper, which is referred to as IMRAD, names the most common paper building blocks, which can be found 
almost in every paper: title, abstract, Introduction, literature review, Methodology, Result and Discussion, Conclusion. However, these blocks do not appear linearly, in the order listed above. Introduction has to clarify the academic context of a paper, therefore, Introduction summarizes student findings of Activities 1-3. After having a first draft of Introduction, students are recommended to start with the most technical and practical parts (e.g. Results), then to introduce the underlying theory (Methodology), then to formulate the Conclusion points and proceed to the Introduction again to verify its structure and to be sure that it suits the rest of the paper quite well.

MRCI (Motivation, Research, Contribution, Implication) framework is a set of questions the author answers during his writing. Having clearly explained all these points, students get a clear view to their research work and can write about it in a clear and concise manner.

As the language support in class some grammar is to be revised, as well as the academic vocabulary, text smoothness and cohesion words and phrases, paragraph structure discussion.

This activity is the core part of the course and lasts for 4-5 weeks.

5. Writing an abstract.

When the paper draft is ready students pass to their abstracts. Knowing how to write an abstract is one of the main skills. It is really the most visible and important part of the paper. Abstract has to reflect exactly what the paper is about and what the author's contribution is. Students are shown that abstracts are self-contained short texts, which synthesize and expose the main points of the paper.

6. Title and checklist.

The title is specially discussed at the end of the writing job; the title should be simple, clear, short, display all the key concepts, straight to the point and powerful. Students also make a checklist to finalize their papers and be sure that all the parts of their papers are properly arranged.

7. Conference management. Program Committee.

In the middle of the semester a conference based on EasyChair platform was registered. Its acronym was AWARE'2017 (Academic Writing and REsearch). The conference program committee (PC) was elected from a number of students, who had strong skills in English. 14 students and teacher were included in the PC, thus, they played two roles: authors and PC members. The paper submission was opened, students created their account at EasyChair and proceeded to abstract and paper submission.

8. Reviewing criteria and code of ethics. Updating camera-ready articles.

In a month before the end of the semester the reviewing process started. The common criteria for reviews were elaborated and the code of ethics was proposed and discussed. The principle goal of reviewing is to improve the papers and comment on it. In practice, the reviews were timely, friendly, thorough and contributed much to improve the papers. Reviewing, thus, was a multichannel knowledge transfer activity, when strong students helped the weaker ones, at the same time the reviewers themselves mastered their critical thinking and reviewing experience.

9. Presentation and talk.

Together with reviewing, speaking skills were also trained to prepare to oral presentation of papers. Students were training phonetics, composing their speech step by step and talking to each other. In order to decrease a number of mistakes in pronunciation, students uploaded the composed pieces to any online IPA (international phonetic alphabet) editor and got them transcribed. Reading by transcription developed the pronunciation skills of students and encouraged them to speak publicly.

10. Presenting the articles at a classroom conference.

Conference environment was created as close to the real as possible. Each of the authors of accepted papers made a 5-7-minute report and was asked questions.

\section{Results and discussion}

The specificity of English skills of master students comprises generally good reading, knowledge of grammar and everyday life conversation. The goal of the ESP course is to develop the specific skills like speaking and listening in professional context, writing in accordance with academic code and reading of a bulk of papers and technical reports, etc. At the same time, master groups have diversity 
in their English skills. The involvement of some students into classroom activities is difficult and implies that they go out their comfort zone. There are students, who are too shy to speak and those, who learn English for many years, but still cannot speak. In this case, a teacher needs some encouraging activity to motivate students.

The authors practise phonetic exercises and some actor training for this purpose. Phonetic training does not require any background, but relaxes students and invokes their positive emotions. Telling tongue twisters and other actor speech exercises also make students to feel the melody of English, to get a new look to it and, as the result, to get a better motivation to proceed with other activities.

To summarize, it is important to note that conference format for ESP classes improves students' motivation as they are exposed to a number of new technologies, they can do some new and unusual activity and, at the same time, they produce a real value, because their papers can be submitted to a real conference in future. All 4 core language skills get improved, none of them is neglected.

The overall number of students enrolled to the ESP course was 50. 35 students attended the classes regularly and composed their articles. Thus, 35 papers were submitted to AWARE'2017 . The reviewing results (Fig. 1) show that $12(\sim 33 \%)$ papers were good enough, while another $11(\sim 33 \%)$ were acceptable, $5(\sim 14 \%)$ papers were rejected for some reasons (either formal or informal), the remaining 7( 20\%) papers were also accepted and their authors presented them as well. The authors of the rejected papers did not present them in public, instead of that, they discussed their papers individually with a teacher and PC members.

\begin{tabular}{|l|l|r|}
\hline \multicolumn{2}{|c|}{ Explanabons of the decisions } \\
\hline decision & explangtion & papers \\
\hline Accept & accept & 12 \\
\hline accept? & probably accept & 11 \\
\hline & no decision & 0 \\
\hline reject? & probably teject & 7 \\
\hline REjEct & pjejed & 5 \\
\hline
\end{tabular}

Fig. 1. Results of reviewing

\section{Conclusions}

1. ESP semester-long class activities are proposed to be put into a conference workflow. All students of master programs have their scientific result based on their Bachelor degree.

2. 10 steps of conference workflow open a wide perspective for practical language skills mastering.

3. Student cooperation and knowledge transfer are very helpful in case of a large diversity of the English competency level.

4. Students acquire a number of side skills useful for their future academic career (LaTeX, BibTeX, CMS, scientific databases, bibliographical managers, etc.).

\section{References}

[1] Kern V. M., Saraiva L. M., dos Santos Pacheco R. C. Peer review in education: promoting collaboration, written expression, critical thinking, and professional responsibility //Education and Information Technologies. №. 1, vol. 8, 2003, pp. 37-46.

[2] Scarcella R. Academic English: A conceptual framework. 2003.

[3] Grab M. O. Embracing Culturally Responsive Methods to Educate Culturally and Linguistically Diverse International Students in the US. - California State University, Long Beach, 2017.

[4] Bailey A. L., Butler F. A. A conceptual framework of academic English language for broad application to education //The language demands of school: Putting academic English to the test. 2007. pp. 68-102. 